\title{
A família no centro das disputas políticas nos Estados Unidos
}

\author{
The Family at the Center of Political Disputes in the United States
}

Rayani Mariano dos Santos' (iD) 0000-0002-6410-7056

'Universidade de Brasília, Programa de Pós-Graduação em Ciência Política, Brasília, DF, Brasil, 70910-900 - secretaria.pospolunb@gmail.com

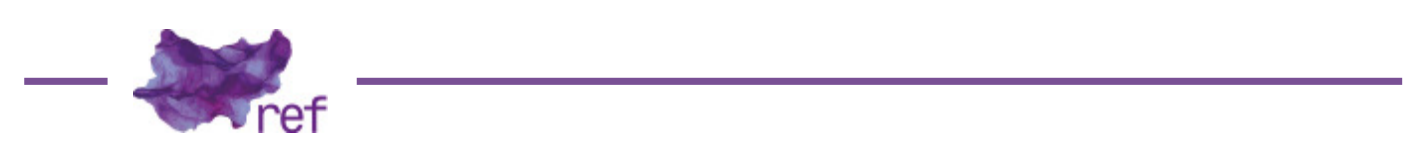

COOPER, Melinda.

Family values: between neoliberalism and the new social conservatism.

New York: Zone Books, 2017.

While neoliberals called for an ongoing reduction in budget allocations dedicated to welfare [...] neoconservatives endorsed an expanding role for the state in the regulation of sexuality. Despite their differences, however, neoliberals and neoconservatives converged on the necessity of reinstalling the family as the foundation of social and economic order. (Melinda COOPER, 2017, p. 49).

O trecho acima sintetiza a centralidade da família na aliança formada nos anos 1970 entre neoconservadores e neoliberais nos Estados Unidos e faz parte do livro Family values: between neoliberalism and the new social conservatism, escrito por Melinda Cooper e publicado em 2017 pela editora Zone Books. Melinda Cooper concluiu seu doutorado em 2001 na Universidade Paris VIII e atualmente é professora na Universidade de Sydney, onde pesquisa financeirização, neoliberalismo e novos conservadorismos sociais.

Family values retoma um longo período, iniciado com a crise de estagflação que atingiu os EUA nos anos 1970 e que vai até o governo de Barack Obama, mostrando a centralidade da família na formação da ordem capitalista pós-keynesiana e para o Estado de bem-estar capitalista. A obra está dividida em sete capítulos que discutem tanto as transformações políticas relativas às famílias quanto as produções teóricas que dialogavam com essas questões.

Cooper (2017) explica que segue a perspectiva de Wendy Brown (2006), para quem o neoliberalismo e o neoconservadorismo devem ser pensados conjuntamente - nas suas convergências, colisões e simbioses - para entender a racionalidade política do poder nos EUA hoje. O neoliberalismo se refere a escolas norte-americanas do novo liberalismo econômico que emergiram em diferentes Universidades dos Estados Unidos, como em Chicago, em Virginia, em Los Angeles e em outras instituições, principalmente nos anos 1960 e 1970. O novo conservadorismo social se refere aos movimentos conservadores que emergiram no final dos anos 1960, incluindo 0 movimento neoconservador, a nova direita religiosa formada por católicos e evangélicos, o novo paternalismo de Lawrence Mead e o movimento comunitarista.

Durante os anos 1970, segundo Cooper (2017), o neoliberalismo e o novo conservadorismo social se juntaram em resposta aos mesmos eventos. O que ocasionou essa aproximação não foi propriamente o Estado de bem-estar social do New Deal, mas os movimentos do final dos anos 1960 que lutavam por uma maior distribuição da riqueza e que recusavam os constrangimentos 
normativos do salário familiar Fordista. Neoliberais e novos conservadores sociais reagiram à crise propondo uma reinvenção estratégica da privatização das responsabilidades familiares.

Enquanto que para os neoconservadores a principal função do Estado era sustentar a família, considerada a base da ordem social, se necessário, pelo uso da força; os neoliberais eram mais simpáticos à ideia de incentivos, como multas ou recompensas, por parte do Estado para que as famílias desempenhassem suas funções tradicionais. Porém, caso os incentivos não fossem suficientes, Cooper (2017) argumenta que eles estavam dispostos a delegar poder aos conservadores sociais para garantir a realização de sua visão de livre-mercado naturalmente equilibrado e uma família espontaneamente autossuficiente. Sob a influência de ambos, o Estado de bem-estar se deslocou de um programa redistributivo para um imenso aparato social com o propósito de policiar a responsabilidade familiar privada dos pobres, ao mesmo tempo em que o déficit orçamentário foi transferido do Estado para a família privada.

Para Cooper (2017), muitos relatos dessa época enxergam a política dos valores familiares como periférica às batalhas econômicas estruturais, ou seja, as guerras de cultura neoconservadora são vistas como meras distrações do objetivo real que é cortar investimento público. Porém a autora discorda dessa visão, e seu livro parte da premissa de que a história das formações econômicas não pode ser analisada sem as operações de gênero, raça e sexualidade, pois se isso ocorrer as próprias políticas de distribuição de renda e riqueza ficam obscurecidas.

Em sua obra, Cooper consegue aliar uma análise das contribuições de teóricos neoliberais e neoconservadores em relação à importância das famílias para seus projetos, ao mesmo tempo em que mostra como diferentes presidentes alteraram programas de bem-estar social durante seus mandatos e como essas transformações serviram para: relembrar as mulheres que sua segurança econômica não era mais responsabilidade do Estado, mas de um homem individual; mostrar o consenso dos partidos Democrata e Republicano em relação ao valor da monogamia; responsabilizar pais ausentes no apoio a crianças fora do casamento etc.

Cooper explica que alguns acadêmicos conservadores viram como consequência da expansão do Estado de bem-estar social a diminuição do papel econômico e moral da família privada. Porém, em contramão a essa ideia, a autora argumenta que os dados empíricos sugerem que a herança é quase tão decisiva no século XXI quanto era no século XIX para a distribuição de riqueza. Para ela, esse fenômeno indica a reafirmação da família privada como uma instituição econômica relevante. Segundo Cooper (2017), as intervenções fiscais e monetárias de Ronald Reagan reabilitaram o valor dos ativos financeiros que estava se depreciando rapidamente nos anos 1970. Ao fazer isso, conforme aponta, o papel da família privada na transmissão de riqueza também foi restaurado.

Além disso, os cortes na educação, saúde e outros serviços sociais transferiram custos de volta para as famílias privadas, e, com o tempo, fortaleceu a ideia de que a democratização da riqueza poderia ser atingida através do crédito. Porém Cooper destaca a questão da educação para mostrar como o crédito não resolve o problema. Nos anos 1960, o crescente investimento público em educação permitiu que um grande número de mulheres, estudantes de baixa renda e minorias entrassem na faculdade, sem precisar do suporte familiar. Contudo, ao longo do tempo, a democratização possibilitada pelo investimento público foi substituída pela democratização do crédito ao consumidor. No entanto, o crédito privado não só obscura os efeitos de classe - com a ideia de que todos podem ter acesso, mas também intensifica a desigualdade, forçando os que não têm renda a pagar taxas mais altas para o mesmo serviço. Quando os custos de longo prazo do crédito começaram a se materializar e acumular, os estudantes foram mais uma vez confrontados com as desigualdades de classe, raça e gênero. As divisões de riqueza familiar se colocaram para esses estudantes com toda sua força histórica.

Outra questão discutida por Cooper é a ascensão do Estado de bem-estar social baseado na fé. Os fornecedores religiosos foram ativamente incluídos nos contratos governamentais para promover diversos serviços, como abrigos para sem teto, cozinhas de sopa, tratamento para dependentes químicos, instrução para paternidade responsável, auxílio nos presídios, entre outros. Segundo Cooper, a terceirização de serviços sociais para organizações religiosas foi implementada de forma restrita nos anos 1960, ganhando força no governo de Bill Clinton (1993-2001), sendo continuada nos governos seguintes de George W. Bush (2001-2009) - que se aliou a evangélicos brancos - e de Barack Obama (2009-2017) - que se aproximou de igrejas negras progressistas em relação à justiça social, mas conservadoras nas questões de gênero.

A preocupação de Cooper em contextualizar de forma detalhada as políticas implementadas nos diferentes governos demonstra que o reforço da responsabilidade familiar não é uma pauta apenas da direita ou de conservadores, mas que atravessa diferentes projetos políticos e ideologias. A autora inicia sua obra, inclusive, criticando teóricas e teóricos que defendem a volta do salário familiar, o que, de uma forma ou de outra, retoma a centralidade da família como instituição, com todos os seus problemas.

Apesar de apresentar uma visão crítica sobre essa idealização do salário familiar e da 
própria família, Cooper não apresenta em seu estudo de que forma essa instituição poderia ser substituída ou transformada. Os dados sobre desigualdade nos Estados Unidos indicam que no século XX, a desigualdade caiu a partir da década de 1930, voltando a subir nos anos 1970 (Thomas PIKETTY; Emmanuel SAEZ, 2014). Nesse sentido, é importante refletir sobre quais políticas poderiam ser implementadas para que os níveis de desigualdade dos anos em que o Estado de bem-estar social prevaleceu nos Estados Unidos fossem retomados sem que seja necessário reforçar um determinado modelo de família.

Outro ponto do livro que merece discussão é a utilização dos termos neoconservadorismo e novo conservadorismo social. Há uma certa confusão na utilização dos termos e, apesar de a autora explicar em determinado momento que o que está chamando de novo conservadorismo social abarca o neoconservadorismo, em outras passagens há a utilização do termo neoconservadorismo como substituto da expressão novo conservadorismo social.

Cabe mencionar ainda que não há consenso na literatura sobre a melhor forma de compreender as relações entre neoliberalismo e conservadorismo social. Como comentado anteriormente, Cooper segue o trabalho de Brown (2006), que considerou neoliberalismo e neoconservadorismo como duas racionalidades distintas. Porém, em livro publicado mais recentemente, Brown (2019) argumentou que a própria racionalidade neoliberal, pensada principalmente a partir da contribuição de Friedrich Hayek, contém uma moralidade tradicional que foi ignorada por muitos autores que compreendem o neoliberalismo apenas da perspectiva da economização de todas as esferas da vida. A mudança na posição de Brown (2019), que está discutindo nesse trabalho a ascensão da extrema direita em diferentes países do mundo nos últimos anos, não interfere na análise realizada por Cooper e indica a atualidade da temática.

A discussão feita por Cooper mostra que gênero, raça e sexualidade não são questões independentes das decisões e políticas econômicas, e que neoliberais se alinharam com conservadores em diferentes momentos da história recente dos EUA para restringir direitos de mulheres e da população LGBT. Apesar de o livro tratar do contexto norte-americano, a implementação de políticas neoliberais concomitante a tentativas de reinstalar a família tradicional é um fenômeno que parece cada vez mais atual, motivo pelo qual a obra de Cooper se torna ainda mais relevante.

\section{Referências}

BROWN, Wendy. "American Nightmare: Neoliberalism, Neoconservatism and De- Democratization". Political Theory, v. 34, n. 6, p. 690-714, dez. 2006.

BROWN, Wendy. In the ruins of neoliberalism: the rise of antidemocratic politics in the west. New York: Columbia University Press, 2019.

COOPER, Melinda. Family values: between neoliberalism and the new social conservatism. New York: Zone Books, 2017.

PIKETTY, Thomas; SAEZ, Emmanuel. "Inequality in the long run”. Science, v. 344, p. 838-843, 2014.

Rayani Mariano dos Santos (rayanimar@gmail.com) é doutora pelo Programa de PósGraduação em Ciência Política da Universidade de Brasília, e sua tese analisa as disputas sobre família na Câmara dos Deputados do Brasil. É mestra pelo mesmo programa, tendo analisado o debate sobre aborto na Câmara dos Deputados entre 1990 e 2014 na dissertação. É graduada em Jornalismo pela Universidade Federal de Santa Catarina.

\section{COMO CITAR ESSE ARTIGO DE ACORDO COM AS NORMAS DA REVISTA}

SANTOS, Rayani Mariano dos. "A família no centro das disputas políticas nos Estados Unidos". Revista Estudos Feministas, Florianópolis, v. 28, n. 2, e67756, 2020.

\section{CONTRIBUIÇÃO DE AUTORIA}

Não se aplica.

\section{FINANCIAMENTO}

O presente trabalho foi realizado com apoio da Coordenação de Aperfeiçoamento de Pessoal de Nível Superior - Brasil (CAPES) - Código de Financiamento 001. 


\section{CONSENTIMENTO DE USO DE IMAGEM}

Não se aplica.

\section{APROVAÇÃO DE COMITÊ DE ÉTICA EM PESQUISA}

Não se aplica.

CONFLITO DE INTERESSES

Não se aplica.

\section{LICENÇA DE USO}

Este artigo está licenciado sob a Licença Creative Commons CC-BY International. Com essa licença você pode compartilhar, adaptar, criar para qualquer fim, desde que atribua a autoria da obra.

HISTÓRICO

Recebido em 25/09/2019

Aprovado em 08/12/2019 